\title{
Artritis por Parvovirus B19. Caso clínico
}

\author{
MARÍA ÁNGELA CARREÑO ${ }^{1,2}$, EDUARDO WAINSTEIN ${ }^{1,3}$, \\ PATRICIA ABUMOHOR ${ }^{1}$
}

\section{Parvovirus B19 arthritis. Report of three cases}

Parvovirus B19 infection is highly prevalent in children and the most common manifestation is a facial rash. In adults, acute polyarthritis and skin rash are often the presenting features. We report three patients with the disease. A 40-year-old female presenting with fever, myalgias and painful swelling of elbows, knees, wrists and feet, with functional limitation, after having a respiratory infection. Additionally, an erythematous skin rash appeared in both extremities. IgM antibodies against Parvovirus B19 were positive. The skin biopsy disclosed a leukocytoclastic vasculitis. The patient was treated with anti-inflammatory drugs and antihistaminics. A 40-year-old female, presenting with skin rash and pain in wrists and hands. IgM antibodies against parvovirus were positive. The patient was treated successfully with acetaminophen. A 38-year-old male with psoriasis, presenting with generalized and progressive polyarthralgia. A Parvovirus viral load determination found 239000 copies of the virus and IgM antibodies were positive. He was successfully treated with non-steroidal anti-inflammatory drugs.

(Rev Med Chile 2012; 140: 1453-1456).

Key words: Arthritis, reactive; Arthritis, infectious; B arthritis, infectious; Parvovirus B 19 human.

E n reumatología es frecuente la consulta por poliartritis aguda, definida como dolor e inflamación de 4 o más articulaciones o grupos articulares por un período menor a seis semanas. Las causas son variadas, como crisis por cristales poliarticulares, artritis infecciosas o reactivas o el inicio de enfermedades del mesénquima como artritis reumatoide, entre otras.

En las infecciones virales frecuentemente existe dolor e inflamación articular, generalmente simétricas y acompañadas de rash cutáneo. Su presencia e intensidad dependen tanto de los factores del huésped como del mismo virus causal ${ }^{1}$. Existen numerosos virus capaces de producir una enfermedad aguda autolimitada con gran compromiso articular, como el Parvovirus B19, virus rubeola, virus hepatitis $\mathrm{B}$ y $\mathrm{C}$ y el virus de la inmunodeficiencia humana, entre otros ${ }^{2}$.

\section{Caso 1}

Mujer de 40 años, sin antecedentes de importancia. Casada, 3 hijos entre 4 y 7 años; el menor presentó infección respiratoria alta, febril, autolimitada. Dos semanas más tarde, la paciente inicia cuadro de fiebre, mialgias generalizadas y cervicalgia posterior. Al quinto día se agrega rash cutáneo eritematoso en extremidades y al séptimo día dolor, aumento de volumen e impotencia funcional de muñeca derecha y ambas rodillas; posteriormente se agregan muñeca izquierda, manos, codos, hombros, tobillos y pies. En consulta inicial se realizan exámenes: hemograma con recuento de leucocitos de 5.380 con $9 \%$ de linfocitos, $81 \%$ segmentados, $6 \%$ baciliformes; VHS $31 \mathrm{~mm} /$ hora; función renal y hepática conservadas; examen de orina normal. Estudio inmunológico: anticuerpos antinucleares (ANA) por IFI en células Hep-2 positivo, título 1: 640, patrón homogéneo, anti-ENA negativos, anti-DNA por IFI positivo débil, complemento C3 normal y C4 disminuido. Posteriormente, consultó en Reumatología donde en el examen físico se constató a nivel cutáneo rash extenso palpable, confluente. El examen cardiopulmonar y abdominal era normal. En el 
examen articular se encontró sinovitis de las articulaciones ya mencionadas. Se solicitó serología para Parvovirus B19 que resultó IgM positivo. Por lo extenso del compromiso cutáneo, la paciente consultó a dermatólogo quien realizó biopsia de las lesiones cutáneas, informándose vasculitis leucocitoclástica. Se inició tratamiento sintomático con antiinflamatorios y antihistamínicos con respuesta tórpida inicial y posterior resolución completa a la sexta semana. Luego de 1 año de seguimiento la paciente persiste asintomática. No se tiene información de exámenes inmunológicos posterior a la resolución del cuadro.

\section{Caso 2}

Mujer de 40 años, casada, sin hijos. Sin antecedentes de importancia. Inició rash cutáneo en extremidades levemente pruriginoso. Al día siguiente presentó dolor e impotencia funcional de manos y muñecas, leve rigidez matinal, por lo que consultó. En el examen físico destacaba a nivel cutáneo, escasas lesiones eritematosas en antebrazos, no palpables, confluentes. El examen cardiopulmonar y abdominal era normal, y en el examen articular se evidenció sinovitis de muñecas, metacarpofalángicas e interfalángicas proximales de ambas manos. Laboratorio: hemograma normal, función hepática y renal conservadas. Se solicitó serología para Parvovirus B19 que resultó IgM positivo. Recibió tratamiento sintomático con paracetamol con resolución completa a las 48 horas. Luego de 1 mes de seguimiento la paciente se mantuvo asintomática.

\section{Caso 3}

Hombre de 38 años, casado, 4 hijos entre 3 y 9 años. Antecedentes de psoriasis cutánea. Inició poliartralgias y mialgias generalizadas, progresivas, sin fiebre ni rash cutáneo, sin otros síntomas. Consultó a las 2 semanas. No refería cuadros febriles en su familia días previos al inicio del cuadro. Examen físico: lesiones cutáneas pequeñas aisladas tipo psoriáticas; examen cardiopulmonar y abdominal normal; examen articular con sinovitis de carpos e interfalángicas proximales de manos. Laboratorio: hemograma con leucocitos 3.470, fórmula diferencial normal; VHS $6 \mathrm{~mm} / \mathrm{h}$; PCR normal. Perfil bioquímico: transaminasa pirúvica $52 \mathrm{mg} /$ $\mathrm{dl}$, transaminasa oxalacética $41 \mathrm{mg} / \mathrm{dl}(<31 \mathrm{mg} / \mathrm{dl})$; resto normal. Carga viral Parvovirus B19:239.000 copias; serología IgM positivo. ANA y factor rema- toídeo (FR): negativos. Recibió anti-inflamatorios no esteroidales con mejoría progresiva y resolución completa a las dos semanas. Luego de meses de seguimiento, el paciente persiste asintomático.

\section{Discusión}

El Parvovirus B19 es encontrado con relativa frecuencia en reumatología, siendo causal de $3,3 \%$ de los pacientes con artritis reactiva aguda ${ }^{3}$. Últimamente se ha involucrado a este virus como factor etiopatogénico en algunas enfermedades reumatológicas, como artritis reumatoide $(\mathrm{AR}) \mathrm{y}$ lupus eritematoso sistémico (LES).

Es miembro del género Erythrovirus de la familia Parvoviridae. Es un virus pequeño con una cadena simple de ADN que codifica dos proteínas estructurales (VP1 y VP2) y una proteína no estructural (NS1) ${ }^{4}$. Su receptor es el antígeno $\mathrm{P}$ o globósido, presente en eritrocitos, eritroblastos, megacariocitos, células endoteliales y células hepáticas y cardiacas fetales. Al parecer, requiere de un co-receptor (la integrina alfa5betal) para la unión del virus a la superficie celular, el cual se encontraría en altas concentraciones sólo en células progenitoras de la línea eritroide, dando un carácter selectivo de replicación en estas células. Esta replicación ha sido demostrada sólo en células progenitoras eritroides humanas presentes predominantemente en la médula ósea ${ }^{4-6}$. Existen individuos que no poseen el antígeno $\mathrm{P}$, lo que les otorga inmunidad innata ${ }^{6}$.

La vía de transmisión es principalmente respiratoria por secreciones; también puede ser vía sanguínea o sus derivados o vía transplacentaria. Está presente en todo el mundo y presenta pequeñas pandemias durante la primavera en intervalos de varios años. La infección es muy común en niños entre los 5 y 15 años, aunque también se puede presentar en adultos, siendo los de mayor riesgo aquellos que trabajan en el cuidado de niños o los padres ${ }^{3}$. En los estudios de prevalencia, revelada por la presencia de anticuerpos IgG contra el virus, se evidencia un aumento en los grupos de mayor edad $^{7}$. En Chile se estudió la prevalencia de anticuerpos IgG contra este virus en 400 donantes de sangre mayores de 18 años en 2 hospitales de Santiago, encontrándose una prevalencia de $54,8 \%{ }^{8}$.

Si bien la mayoría de las infecciones son asintomáticas, la manifestación clínica depende de la 
edad y del estado hematológico e inmunológico del huésped ${ }^{3}$. El diagnóstico de la infección aguda se basa en la detección serológica de anticuerpos IgM contra las proteínas estructurales VP1 y VP2, los cuales tienen una duración de 1-3 meses aunque en algunos pacientes pueden persistir hasta por seis meses o más. La sensibilidad y especificidad de este examen depende del kit comercial en que se realice y en general, superan el $90 \%$. En pacientes inmunocomprometidos es recomendable realizar la detección directa de productos virales mediante reacción de polimerasa en cadena $(\mathrm{PCR})^{3,4}$. El período de incubación dura 6-18 días, pudiendo extenderse hasta 28 días, durante el cual se produce la viremia. En $68 \%$ de los casos no hay manifestaciones clínicas, pudiendo provocar síntomas leves como fiebre transitoria, malestar general, mialgias y cefalea. En este período aparecen las manifestaciones hematológicas, caracterizada por areticulocitosis profunda que se produce en el peak de la viremia, entre el día 10 y 12 post infección. Posteriormente, puede aparecer neutropenia, linfopenia y trombocitopenia, llegando a manifestaciones más graves en pacientes susceptibles, como aplasia pura de células rojas en inmunocomprometidos o crisis aplástica transitoria en pacientes con anemia de células falciformes $\mathrm{u}$ otras anemias hemolíticas. Esta areticulocitosis se produce hasta la aparición de los anticuerpos IgM específicos contra el virus el día 15-18 post infección. Junto con esto, aparecen las manifestaciones articulares (artralgia o artritis) y cutáneas (rash), las cuales estarían mediadas por complejos inmunes. A menudo se acompañan de malestar general y síntomas gastrointestinales. El rash cutáneo aparece en $50 \%$ de los casos, a menudo pruriginoso y tiene una duración de 3-4 días. Las manifestaciones articulares son más frecuentes en los adultos, principalmente mujeres. Ochenta por ciento de los adultos infectados puede tener artralgias y $60 \%$ artritis, principalmente en las interfalángicas proximales de manos, metacarpofalángicas, muñecas, rodillas y tobillos, que luego se puede generalizar y presentar importante rigidez matinal ${ }^{1,3}$; generalmente se resuelve en dos semanas. En algunas ocasiones puede evolucionar como un cuadro crónico que incluso puede causar erosiones y destrucción articular, pudiendo asociarse a la presencia de $\mathrm{FR}^{3}$. Esta condición estaría influenciada por la persistencia del virus circulante y por una escasa respuesta en la generación de anti- cuerpos IgG $\mathrm{G}^{1}$. El tratamiento de la infección aguda es sintomático con antiinflamatorios no esteroidales y su pronóstico a largo plazo es bueno. En casos de supresión de médula ósea y en persistencia del virus en pacientes inmunosuprimidos, el uso de inmunoglobulina ha demostrado ser beneficioso ${ }^{1}$.

Las infecciones virales pueden provocar reacciones inmunológicas y gatillar enfermedades autoinmunes en personas genéticamente susceptibles. Específicamente, durante la infección por Parvovirus B19 se ha detectado la presencia de autoanticuerpos en títulos leves a moderados, como ANA, FR, anti-DNA, anti-citoplasma de neutrófilos (ANCA), anti-mitocondriales, anti-músculo liso, anti-células parietales y anti-fosfolípidos sin manifestaciones a largo plazo de enfermedad inmunológica ${ }^{1,3,4}$. Existen reportes en que se ha descrito la asociación de esta infección a enfermedades autoinmunes, como AR, LES, artritis idiopática juvenil, esclerosis sistémica progresiva, artritis reactiva, síndrome de Sjögren, cirrosis biliar primaria, polimiositis-dermatomiositis, citopenias autoinmunes y vasculitis ${ }^{4}$. La persistencia del virus en el organismo participaría en la iniciación y perpetuación de la AR para lo cual se han propuesto distintos mecanismos: depósito de complejos inmunes en la membrana sinovial, inducción de inmunidad por mimetismo molecular, citotoxicidad y producción de citoquinas inflamatorias (TNF-alfa e interleuquina-6), producción de anticuerpos y alteración de la inmunidad celular secundaria a la respuesta antiviral ${ }^{3,4}$. Para el LES se han propuesto otros mecanismos: los anticuerpos anti-ADN producidos por las células $B$ activadas hidrolizan el ADN del virus presente en el suero o en las células en replicación. Este ADN hidrolizado provoca muerte celular con posterior exposición de nuevos antígenos al sistema inmunológico, perpetuando la activación de la enfermedad ${ }^{6}$.

\section{Conclusión}

La poliartritis aguda constituye un desafío diagnóstico en reumatología debido a los distintos factores causales, dentro de los cuales los virus forman parte importante del estudio. Específicamente, creemos que la búsqueda del Parvovirus B19 mediante serología específica ante la presencia de un cuadro de poliartritis aguda es importante, debido a que las manifestaciones clínicas de la in- 
fección son similares a la presentación de algunas enfermedades inmunológicas, y por su capacidad potencial de gatillar enfermedades autoinmunes en pacientes genéticamente susceptibles.

\section{Referencias}

1. Stanley JN. Viral Arthritis. En: Firestein GS, Budd RC, Harris ED Jr, McIlnnes IB, Ruddy S, Sergent JS, Editores, Kelley's Textbook of Rheumatology. Eighth Edition. Filadelfia, EEUU: Editorial Saundres Elsevier; 2009. p. 1761-70.

2. Leonard H, Calabrese, DO. Infectious Disorders, B. Viral Arthritis. En: Klippel JH, Stone JH, Crofford LJ, White PH, Editores. Primer on the rheumatic diseases. Thirteenth Edition. Atlanta, EEUU: Editorial Springer; 2008. p. 277-81.

3. Colmegna I, Alberts-grill N. Parvovirus B19: Its role in
Chronic Arthritis. Rheumat Dis Clin of N Am 2009; 35: 95-110

4. Lunardi C, Tinazzi E, Bason C, Dolcino M, Corrocher R, Puccetti A. Human parvovirus B19 infection and autoimmunity. Autoimmun Rev 2008; 8: 116-20.

5. Brown E. [The expanding range of parvoviruses which infect humans.] Rev Med Virol 2010; 20: 231-44.

6. Pavlovic M, Kats A, Cavallo M, Shoenfeld Y. Clinical and Molecular Evidence for Association of SLE with parvovirus B19. Lupus 2010; 18: 783-92.

7. Kelly H.A, Siebert D, Hammond R, Leydon J, Kiely P, Maskill W. The age-specific prevalence of human parvovirus immunity in Victoria, Australia compared with other parts of the world. Epidemiol Infect 2000; 124: 449-57.

8. Gaggero A, Rivera J, Calquín E, Larrañaga CE, León O, Díaz P, et al. Seroprevalencia de anticuerpos IgG contra parvovirus B19 en donantes de sangre de hospitales en Santiago, Chile. Rev Med Chile 2007; 135: 443-8. 